\title{
Calcium-sensing receptor gene polymorphism is not associated with bone mineral density in Italian postmenopausal women
}

\author{
F Cetani, E Pardi, S Borsari, E Vignali, G Dipollina, V Braga ${ }^{1}$, S Adami ${ }^{1}$, A Pinchera and C Marcocci \\ Dipartimento di Endocrinologia e Metabolismo, Ortopedia e Traumatologia, Medicina del Lavoro, Università di Pisa, Pisa, Italy and ${ }^{1}$ Dipartimento di \\ Reumatologia, Valeggio sul Mincio, Università di Verona, Verona, Italy
}

(Correspondence should be addressed to C Marcocci; Email: c.marcocci@endoc.med.unipi.it)

\begin{abstract}
Objective: Calcium-sensing receptor ( $\mathrm{CaR})$ is a candidate gene for osteoporosis susceptibility. Several $\mathrm{CaR}$ polymorphisms have been identified and an association between the A986S genotype and serum calcium levels has been found in Canadian postmenopausal women. We investigated whether the presence of $986 \mathrm{~S}$ allele was associated with bone mineral density (BMD) and osteoporotic fractures.

Design: The study group consisted of 164 Italian postmenopausal women without fragility fracture $\left(\mathrm{Fx}^{-}\right)$and 55 women with fracture $\left(\mathrm{Fx}^{+}\right)$.

Methods: A fragment of exon 7 of CaR gene containing three polymorphisms (A986S, R990G and Q1011E) was amplified by PCR and sequenced. Anthropometric characteristics and BMD were evaluated.

Results: The A986S polymorphism was the most commonly observed (27.9\%), whereas the other two CaR polymorphisms, R990G and Q1011E, occurred in a minority of cases $(8.8$ and $5.5 \%$ respectively). There was no significant difference in the frequency distribution of any $\mathrm{CaR}$ allele between $\mathrm{Fx}^{-}$and $\mathrm{Fx}^{+}$patients. Body mass index was found to predict BMD at the lumbar spine and femoral neck. The A986S polymorphism and years since menopause were not independent predictors of BMD at any site. As far as fracture occurrence, there was no statistically significant difference in the prevalence of fractures between women carrying or not carrying the $986 \mathrm{~S}$ allele.

Conclusions: Our data do not support a role of A986S CaR polymorphism in BMD and in the prevalence of fragility fractures in Italian postmenopausal women.
\end{abstract}

European Journal of Endocrinology 148 603-607

\section{Introduction}

Osteoporosis is a common disease characterized by reduced bone mineral density (BMD), architectural deterioration of bone tissue and increased fracture risk (1). Low BMD is an important risk factor for fractures, the clinically most relevant feature of osteoporosis. BMD is determined by the interaction of genetic, metabolic and environmental factors. In the past years, twin and family studies have suggested that BMD has a strong genetic component $(2-4)$ and is under a polygenic control $(5,6)$. Many candidate genes involved in the control of calcium homeostasis have been suggested and evaluated for their association with BMD and risk of fragility fracture (7).

Calcium-sensing receptor $(\mathrm{CaR})$ is expressed in bone cells and/or their precursors, including osteoblasts, osteoclast precursors, mature osteoclasts and osteocytes. Osteoclast's bone-resorbing activity is regulated by extracellular $\mathrm{Ca}^{2+}$ concentration within the resorption lacunae, and there is some evidence suggesting that this effect is mediated by CaR (8). Moreover, CaR might influence bone mass indirectly, through its effects on parathyroid hormone secretion and calcium balance (9).

Several CaR polymorphisms have been identified (A986S, R990G and Q1011E) and some studies (10), but not others $(11,12)$, have found an association between the $986 \mathrm{~S}$ allele and serum calcium levels. Although no data are available on the functional effect of this polymorphism, it might be speculated that, in addition to regulating serum calcium levels, this polymorphism might also influence bone remodeling and BMD. In this regard, a very recent study has found no association between A986S polymorphism and BMD in Hungarian postmenopausal women (13).

We have recently shown that the A986S polymorphism occurs frequently in healthy Italian subjects (12). In the present study we investigated the A986S polymorphism in a large panel of Italian postmenopausal 
women and evaluated whether the presence of $986 \mathrm{~S}$ polymorphic allele was associated with BMD and osteoporotic fractures.

\section{Materials and methods}

\section{Subjects}

A cohort of 544 Caucasian postmenopausal women was recruited for osteoporotic risk evaluation within a specific project of the Veneto Region (Progetto Invecchiamento) (14). This study included unrelated women aged 69-74 years participating in a population-based longitudinal epidemiological investigation. The subjects were randomly selected with the collaboration of the general practitioner, with a final participation rate of $77 \%$. This population was shown to be a homogeneous ethnic community with a welldefined genetic entity, clearly separable from the other Italian regions (15). Subjects $(n=49 ; 9.0 \%)$ with a history of diseases or treatment with drugs known to affect bone mass and metabolism (including bisphosphonate and estrogens) (14), dietary calcium intake less than $500 \mathrm{mg} /$ day, alcohol abuse (more than one unit per day), and smoking more than ten cigarettes/ day were excluded. At the initial evaluation, height and weight were measured using a stadiometer and a calibrated balance-beam scale. Dietary calcium intake was estimated using a 7-day questionnaire on dairy product intake and assuming that the daily calcium intake from non-dairy products was $400 \mathrm{mg}$. Four hundred and ninety-five women were submitted to further evaluation, including BMD and past history of lowtrauma fracture occurring after the age of 50 years. A lateral X-ray of the spine was obtained from $72 \%$ of them. The method of McCloskey was used to evaluate the presence of vertebral fractures on spine radiographs (16). Four hundred and forty women were without fracture and 55 had evidence of prevalent fragility fractures (10 hip, 15 wrist, 27 spine, two ribs and one pelvic).
The study group consisted of 164 women randomly selected by computer-generated random numbers from the 440 women without fracture $\left(\mathrm{Fx}^{-}\right)$and of the 55 women with vertebral and non-vertebral fractures $\left(\mathrm{Fx}^{+}\right)$(Table 1).

The patients gave informed consent and the local Ethical Committee approved the study.

\section{Genotyping}

Genomic DNA from all subjects was extracted from peripheral white blood cells using standard proteinase $\mathrm{K}-\mathrm{SDS}$ digestion and phenol-chloroform extraction. DNA samples were kept at $-20^{\circ} \mathrm{C}$ until used.

A fragment of exon 7 of $\mathrm{CaR}$ gene containing the three polymorphisms (A986S, R990G and Q1011E) was amplified by PCR with the following primers: forward 5/TCCCGCAACACCATCGAGGA, and reverse 5'TCTTCCTCAGAGGAAAGGAG. At least two different PCR amplifications from genomic DNA were sequenced on double strands with sense and antisense primers. Reverse primers were biotinylated. PCR was performed as previously described (17).

Contamination problems were ruled out by including PCR control samples with no DNA as template. Extraction of DNA and pre-PCR reactions were performed in different rooms with respect to post-PCR reactions.

\section{BMD}

BMD was measured by dual energy X-ray absorptiometry (using two different types of equipment (Hologic QDR 2000 and 4500 instruments; Hologic, Inc., Waltham, MA, USA)) at the lumbar spine (anteriorposterior, L2-L4) and femoral neck. Calibration was performed daily and a lumbar spine phantom was scanned at least twice a week. Cross-calibration of the two types of equipment, both in vivo and in vitro, indicated that a correction factor was unnecessary. The coefficients of variations were less than $1.3 \%$ for both instruments at all skeletal sites. BMD was

Table 1 Antropometric characteristics and BMD values (mean \pm S.D.) of the study group.

\begin{tabular}{|c|c|c|c|c|}
\hline & All & Without fractures $\left(\mathrm{Fx}^{-}\right)$ & With fractures $\left(\mathrm{Fx}^{+}\right)$ & $\boldsymbol{P}$ \\
\hline Number of subjects & 219 & 164 & 55 & - \\
\hline Age (years) & $63.9 \pm 8.2$ & $63.1 \pm 8.3$ & $66.4 \pm 7.5$ & 0.02 \\
\hline $\mathrm{BMI}\left(\mathrm{kg} / \mathrm{m}^{2}\right)$ & $25.9 \pm 4.4$ & $26.0 \pm 4.5$ & $25.4 \pm 4.1$ & 0.3 \\
\hline Years since menopause & $14.5 \pm 8.9$ & $13.2 \pm 8.9$ & $17.6 \pm 8.0$ & $<0.001$ \\
\hline \multicolumn{5}{|l|}{ Lumber spine* } \\
\hline BMD & $0.83 \pm 0.16$ & $0.85 \pm 0.16$ & $0.75 \pm 0.12$ & 0.001 \\
\hline T-score & $-2.22 \pm 1.5$ & $-2.04 \pm 1.53$ & $-3.01 \pm 1.12$ & $<0.001$ \\
\hline Z-score & $-0.56 \pm 1.41$ & $-0.42 \pm 1.41$ & $-1.15 \pm 1.29$ & 0.006 \\
\hline \multicolumn{5}{|l|}{ Femoral neck } \\
\hline BMD & $0.58 \pm 0.15$ & $0.60 \pm 0.16$ & $0.50 \pm 0.12$ & $<0.001$ \\
\hline T-score & $-2.44 \pm 1.34$ & $-2.23 \pm 1.37$ & $-3.06 \pm 1.06$ & $<0.001$ \\
\hline Z-score & $-0.49 \pm 1.28$ & $-0.31 \pm 1.29$ & $-1.01 \pm 1.08$ & $<0.001$ \\
\hline
\end{tabular}

*Data were available for 192 subjects. 
expressed as an areal density in $\mathrm{g} / \mathrm{cm}^{2}$, and $\mathrm{T}$ - and Z-scores (difference from the mean BMD value of healthy young people or aged-matched individuals divided by their S.D. respectively).

\section{Statistical analysis}

An unpaired $t$-test was used to compare different continuous variables between subjects grouped according to the absence or presence of fragility fractures. Subjects were also divided according to their $\mathrm{CaR}$ and the frequency and association with fragility fractures were evaluated using $\chi^{2}$. Multiple linear regression was employed to predict the effect of continuous variables (age, body mass index (BMI), years since menopause (YSM)) and CaR polymorphisms on BMD. Differences were considered significant at $P<0.05$. Our study has a power of 0.8 to detect a difference of 0.65 for lumbar T-score, and a difference of 0.58 for femoral neck T-score.

\section{Results}

BMD measurement at the femoral neck was available in all women. At variance, lumbar spine BMD was available only in 192 (87.7\%). The clinical characteristics are reported in Table $1 . \mathrm{Fx}^{+}$patients were slightly but significantly older than $\mathrm{Fx}^{-}$patients; no difference was observed in BMI. In $\mathrm{Fx}^{-}$patients, BMD values at the lumbar spine and femoral neck were strongly related to age, BMI and YSM $(P<0.0001$ for all three independent variables; data not shown). As expected, BMD values, T-scores and Z-scores were significantly lower in $\mathrm{Fx}^{+}$patients compared with $\mathrm{Fx}^{-}$.

The frequency distribution of the three CaR polymorphisms in the study group was in agreement with the Hardy-Weinberg equilibrium $(P$ values were $0.78,0.60$ and $>0.99$ for the A986S, R990G and Q1011E polymorphisms respectively) (Table 2). The A986S polymorphism was the most commonly observed $(27.9 \%)$, whereas the other two CaR polymorphisms, R990G and Q1011E, occurred in a minority of cases (8.8 and 5.5\% respectively).
For statistical analysis, patients heterozygous or homozygous for the $\mathrm{S}$ allele were combined. There was no significant difference in the frequency distribution of any CaR allele between $\mathrm{Fx}^{-}$and $\mathrm{Fx}^{+}$ patients.

We further investigated whether the CaR polymorphism might have an impact on BMD values and prevalence of fractures. Because of the low frequency of the 990G and 1011E alleles the analysis was limited to the $986 \mathrm{~S}$ allele. The independent contribution to the variation of BMD was evaluated in $\mathrm{Fx}^{-}$patients using multiple regression analysis. As indicated in Table 3, BMI was found to predict BMD at the lumbar spine and femoral neck; age only predicted femoral neck BMD. The A986S polymorphism and YSM were not independent predictors of BMD at both sites. As far as fracture occurrence, there was no statistically significant difference in the prevalence of fractures between women carrying or not carrying the $986 \mathrm{~S}$ allele $(P=0.33)$ (Fig. 1). The power of detecting a significant association between the A986S polymorphism and prevalence of fracture was 0.20 .

\section{Discussion}

Calcium homeostasis has an important role in the regulation of bone remodeling and alterations of the mechanisms involved in its regulation may contribute to the development of metabolic bone diseases (8). Most candidate genes have been evaluated in small-sample studies and conflicting results have been reported in different populations. The use of meta-analysis may overcome these problems. The most promising marker seems to be the COLIA1 Sp1 polymorphism, which appears to predict fracture independently of BMD (7).

Previous studies have suggested that the A986S CaR polymorphism might have functional consequences in calcium homeostasis (10). Indeed, Cole et al. (10) reported an association between the $986 \mathrm{~S}$ allele and serum calcium levels in healthy Canadian postmenopausal women. This finding was not confirmed by two different studies in healthy European postmenopausal women $(11,12)$.

Table 2 Distribution (\%) of the CaR polymorphisms in the study group.

\begin{tabular}{|c|c|c|c|c|}
\hline CaR genotype & All $(n=219)$ & Patient without fractures $\left(\mathrm{Fx}^{-}, n=164\right)$ & Patients with fractures $\left(\mathrm{Fx}^{+}, n=55\right)$ & $\boldsymbol{P}^{*}$ \\
\hline AA & $158(72.1)$ & 115 (70.1) & 43 (78.2) & \\
\hline AS & $54(24.7)$ & $44(26.8)$ & 10 (18.2) & \\
\hline SS & 7 (3.2) & $5(3.1)$ & $2(3.6)$ & \\
\hline AS/SS & $61(27.9)$ & 49 (29.9) & $12(21.8)$ & 0.30 \\
\hline $\mathrm{RR}$ & $200(91.3)$ & $151(92.1)$ & 49 (89.1) & \\
\hline$R G$ & $19(8.7)$ & $13(7.9)$ & $6(10.9)$ & 0.58 \\
\hline GG & 0 & 0 & 0 & \\
\hline$Q Q$ & 207 (94.5) & 154 (93.9) & $53(96.4)$ & \\
\hline QE & $12(5.5)$ & $10(6.1)$ & 2 (3.6) & 0.73 \\
\hline EE & 0 & 0 & 0 & \\
\hline
\end{tabular}

* Wild type vs polymorphic allele according to Fisher's exact test. 
Table 3 Independent predictors of BMD in 164 postmenopausal women. $\beta$ values, $P$ values and $R^{2}$ values are shown.

\begin{tabular}{lccccc}
\hline & \multicolumn{2}{c}{ Lumbar spine } & & \multicolumn{2}{c}{ Femoral neck } \\
\cline { 2 - 3 } \cline { 6 - 6 } & \multicolumn{1}{c}{$\beta$} & & & $\beta$ & $P$ \\
\hline Age & -0.28 & 0.14 & & -0.37 & 0.02 \\
YSM & -0.08 & 0.65 & & 0.06 & 0.72 \\
BMI & 0.27 & $<0.001$ & & 0.39 & $<0.001$ \\
A986S & 0.002 & 0.98 & & 0.01 & 0.86 \\
$\mathrm{R}^{2}$ & 0.19 & $<0.001$ & & 0.30 & $<0.001$ \\
\hline
\end{tabular}

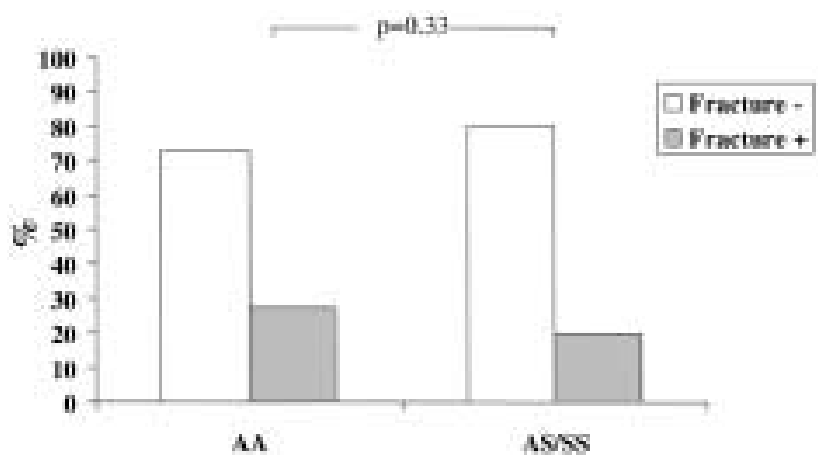

Figure 1 Distribution of the A986S genotype between women with and without osteoporotic fractures.

In the present study we investigated the effect of A986S and two other CaR polymorphisms (R990G and Q1011E) on bone density and osteoporotic fractures in a sample of Italian postmenopausal women. Since the A986S polymorphism was the most commonly observed, attention was paid particularly to its role. Using a multiple linear regression model we found that this polymorphism did not independently predict BMD. On the other hand, in agreement with previous findings, BMI and age were independent predictors of BMD (18). Our findings are in agreement with the results reported by Takacs et al. (13), who have searched for an association between the CaR polymorphism and BMD in 230 Hungarian postmenopausal women. They found no difference in the distribution of the various CaR genotypes between osteoporotic patients and healthy control women. Therefore it appears that the CaR A986S polymorphism does not have a relevant role in BMD in European postmenopausal women. On the other hand, Lorenzon et al. (19) have observed that healthy adolescent girls carrying the $986 \mathrm{~S}$ allele have lower BMD at the lumbar spine and total body, but this association disappeared after adjusting for physical activity. Interestingly, in Japanese postmenopausal women an association between a newly isolated microsatellite (CA repeat polymorphism) at the CaR locus and BMD has been recently described (20). This genotype associated with lower BMD could be in linkage disequilibrium with a mutation either in the CaR gene or in another gene very close to $\mathrm{CaR}$, since the $\mathrm{CA}$ repeat polymorphism is located within $110 \mathrm{~kb}$ of the CaR gene.

We also investigated the effect of the A986S CaR polymorphisms on fragility fractures. We found no difference in the frequency of this polymorphism (as well as of R990G and Q1011E) between postmenopausal women with or without fragility fractures. However, due to the size of our cohort, we cannot draw any definite conclusion as to whether the apparent lack of association between the $986 \mathrm{~S}$ allele and osteoporotic fracture was only due to the low power of the study (0.20) or to true absence of association.

Whether the A986S polymorphism has functional effects is still unanswered and related observations question this hypothesis. Others (11) and we (12) observed no difference in several clinical and biochemical parameters between primary hyperparathyroid patients carrying and not carrying the $\mathrm{S}$ allele.

In conclusion, at present there is no convincing evidence for a role of A986S CaR polymorphism, if any, in the determination of bone mass in Italian postmenopausal women. Further studies aimed at demonstrating a functional effect of this CaR polymorphism in vitro appear to be necessary before additional association studies are performed.

\section{Acknowledgements}

This work was supported in part by the University of Pisa (Fondi di Ateneo to C M), the Ministero dell'Universitàe della Ricerca Scientifica e Tecnologica (Rome, Italy). The authors thank Dr Silvestro Micera for assistance in statistical analysis.

\section{References}

1 Kanis JA, Melton LJ, Christiansen C, Johnston CC \& Khaltaev N. The diagnosis of osteoporosis. Journal of Bone and Mineral Research $198191137-1141$.

2 Pocock NA, Eisman JA, Hopper JL, Yeates MG, Sambrook PN \& Ebert S. Genetic determinants of bone mass in adults: a twin study. Journal of Clinical Investigation $1987 \mathbf{8 0}$ 706-710.

3 Seeman E, Hopper JL, Bach LA, Cooper ME, Parkinson E, McKay J et al. Reduced bone mass in daughters of women with osteoporosis. New England Journal of Medicine 1989320 554-558.

4 Soroko SB, Barret-Connor E, Edelstein S \& Kritz-Silverstain D. Family history of osteoporosis and bone mineral density at the axial skeleton: the Rancho Bernardo Study. Journal of Bone and Mineral Research $19949761-769$.

5 Guéguen R, Jouanny P, Guillemin F, Kuntz C, Pourel J \& Siest G. Segregation analysis and variance components analysis of bone mineral density in healthy families. Journal of Bone and Mineral Research 199512 2017-2022.

6 Livshits G, Pavlovsky O \& Kobyliansky E. Population biology of human aging: segregation analysis of bone age characteristics. Human Biology 199668 539-554.

7 Ralston SH. Genetic control of susceptibility to osteoporosis. Journal of Clinical Endocrinology and Metabolism $2002 \quad 87$ $2460-2466$. 
8 Brown EM \& Macleold RJ. Extracellular calcium sensing and extracellular calcium signaling. Physiological Reviews 200181 239-297.

9 Kameda T, Mano H, Yamada Y, Takai H, Amizuka N, Kobori M et al. Calcium-sensing receptor in mature osteoclasts which are bone resorbing cells. Biochemical and Biophysical Research Communications $1998 \mathbf{2 4 5}$ 419-422.

10 Cole DE, Peltekova VD, Rubin LA, Hawker GA, Vieth R, Liew CC et al. A986S polymorphism of the calcium-sensing receptor and circulating calcium concentrations. Lancet 1999353 112-115.

11 Miedlich S, Lamesch P, Mueller A \& Paschke R. Frequency of the calcium-sensing receptor variant A986S in patients with primary hyperparathyroidism. European Journal of Endocrinology 2001145 $421-427$.

12 Cetani F, Borsari S, Vignali E, Pardi E, Picone A, Cianferotti L et al. Calcium-sensing receptor gene polymorphisms in primary hyperparathyroidism. Journal of Endocrinological Investigation 200225 614-619.

13 Takacs I, Speer G, Bajnok E, Tabak A, Nagy Z, Horvath C et al. Lack of association between calcium-sensing receptor gene 'A986S' polymorphism and bone mineral density in Hungarian postmenopausal women. Bone $200230849-852$.

14 Braga V, Mottes M, Mirandola S, Lisi V, Malerba G, Sartori L et al. Association of CTR and COLIA1 alleles with BMD values in periand postmenopausal women. Calcified Tissue International 2000 $67361-366$
15 Barbujani G \& Sokal RR. Genetic population structure of Italy. American Journal of Human Genetics 199148 398-411.

16 McCloskey EV, Spector TD, Eyres KS, Fern ED, O'Rourke N, Vasikaran $\mathrm{S}$ et al. The assessment of vertebral deformity: a method for use in population studies and clinical trials. Osteoporosis International 1993 3 138-147.

17 Cetani F, Pinchera A, Pardi E, Cianferotti L, Vignali E, Picone A et al. No evidence for mutations in the calcium-sensing receptor gene in sporadic parathyroid adenomas. Journal of Bone and Mineral Research $199914878-882$.

18 Rico H, Arribas I, Casanova FJ, Duce AM, Hernandez ER \& Cortes-Prieto J. Bone mass, bone metabolism, gonadal status and body mass index. Osteoporosis International 200213 379-387.

19 Lorentzon M, Lorentzon R, Lerner UH \& Nordstrom P. Calcium sensing receptor gene polymorphism, circulating calcium concentrations and bone mineral density in healthy adolescent girls. European Journal of Endocrinology $2001144257-261$.

20 Tsukamoto K, Orimo H, Hosol T, Miyao M, Ota N, Nakajima T et al. Association of bone mineral density with polymorphism of the human calcium-sensing receptor locus. Calcified Tissue International 200066 181-183.

Received 25 November 2002 Accepted 17 March 2003 